\title{
HISTÓRIA URBANA A CONFIGURAÇÃO DE UM CAMPO CONCEITUAL
}

\section{URBAN HISTORY \\ The configuration of a conceptual field}

v. 7, n. 10

jan/ago (2015)

ISSN 1982-0569
Amílcar Torrão Filho

Pontifícia Universidade Católica de São Paulo e-mail: amilcartorrao@uol.com.br

Ao definir o espaço de constituição do capitalismo e da modernidade, Fernand Braudel, em seu clássico Civilização Material, Economia e Capitalismo, não hesita em afirmar a cidade como o lócus de construção histórica desta modernidade. As cidades são, para este autor, como transformadores elétricos: elas aumentam as tensões, precipitam as trocas, removem a vida dos homens. São nascidas da mais revolucionária divisão do trabalho: campo de um lado, atividades urbanas do outro. A cidade é cesura, ruptura, destino do mundo. Ao surgir com a escritura ela abre as portas para a história; quando renasce na Europa no séc. XI a ascensão do continente começa, quando ela floresce na Itália, é o Renascimento. Tão importante quanto seu conceito de longa duração, muitas vezes referenciado entre historiadores e cientistas sociais, Braudel ao dar tamanha importância ao espaço e à cidade também pensou num conceito que desse conta da dinâmica que envolve a cidade e a história, a pouco citada longa dimensão. A vida da cidade está associada a um espaço de longa dimensão, de onde vêm seus homens, onde estão suas relações comerciais, cidades, vilas e mercados que aceitam os seus pesos e medidas ou suas moedas, ou que falam a sua língua dialetal (s.d.: 5601). De onde ela imperiosa, imperial e imperativamente tira seu sustento, sua mão-deobra, seu exército industrial de reserva, seu poder. "No Ocidente, capitalismo e cidades, no fundo, são a mesma coisa", afirma o historiador francês (s.d.: 586).

A cidade é um espaço de densidade teórica e temporal complexa, um objeto de saberes e de práticas que compõem imagens, memórias e ações diversas. Do ponto de vista temporal, como recorda Lepetit, ela é composta por uma complexidade e uma 
CIEC

"pluralidade de tempos descompassados, cuja combinação gera mudança a cada instante"; além disso, os elementos de uma cidade têm idades diferentes. A rede viária é mais duradoura do que o loteamento, o lote dura mais do que as casas construídas nele, os vazios duram mais do que os cheios, as estruturas menos materiais duram mais que o construído (LEPETIT, 2001: 139). Assim como a Zaíra de Calvino, a cidade "se embebe como uma esponja dessa onda que reflui das recordações e se dilata". Sua descrição que deveria conter todo o seu passado, entretanto, não o conta, "ela o contém como as linhas da mão, escrito nos ângulos das ruas, nas grades das janelas, nos corrimões das escadas (...)" (CALVINO, 1994: 14-15). Trata-se, portanto, de uma temporalidade e uma espacialidade com múltiplas subordinações e associações, que não se esgotam na descrição de seus processos morfológicos ou de suas realizações técnicas. A cidade vista como palimpsesto, como uma superposição de técnicas construtivas, estilos arquitetônicos ou ciclos econômicos é, para Lepetit, uma solução fácil, na qual a sua "compreensão se esgotaria no achado dos vestígios antigos sobre a escrita mais recente". Uma atividade de antiquário, na qual a história seria capaz de contribuir muito pouco. Mais do que a observação empírica das transformações concretas da cidade, trata-se de dar "aos usos sociais da cidade a mesma atenção classificatória que se dedicou às formas urbanas" (LEPETIT, 2001: 140).

É da analogia das camadas geológicas presentes na configuração do espaço e do tempo histórico da longa duração tal como formulada por Fernand Braudel que Lepetit retira sua metáfora geomorfológica da cidade, como resultado do "rearranjo permanente de falhas múltiplas", no qual as formas antigas são "constantemente retomadas pelas sociedades em novas construções"; uma rede de "realidades sobrepostas umas às outras" na qual as mudanças espaciais se operam num "jogo de atualizações sucessivas das formas passadas em combinações territoriais novas" (LEPETIT, 2001: 146). É da extensão territorial e temporal proposta por Braudel, ao tratar todo o mundo mediterrâneo em uma escala temporal de vários séculos como seu objeto, que Lepetit propõe a sua abordagem do urbano. Por isso uma relação dialética da memória com a cidade: por um lado a memória coletiva se apoia em imagens espaciais; por outro, os grupos sociais inscrevem na cidade suas lembranças, definindo um quadro espacial. O presente é o tempo no qual a vontade individual e a norma coletiva se defrontam e se ajustam. Ao trazer a análise teórica e metodológica da história para a cidade, Lepetit não diminui a escala continental de Braudel, mas atualiza 
esta escala para um espaço sintético das formações sociais e econômicas; "cada escala informa um nível de explicação particular" (LEPETIT, 1989: 1321).

A cidade é central, ainda, por ser o habitat do homem, esta "pátria artificial", este "depósito de fadigas", de que nos fala Aldo Rossi, resultante do trabalho e do engenho humanos, além de "testemunho de valores", "permanência e memória". "A cidade é na sua história" (2001: 22). A historicidade da cidade consiste em sua densidade espacial, temporal, material e teórica. Rossi não nos remete apenas aos edifícios, "momentos ou partes de um todo que é a cidade" (2001: 24), mas ao seu conhecimento concreto, em sua inteireza, para além da tipologia e da função. Sendo assim, ele propõe uma "visão globalizante da cidade", uma "compreensão de sua estrutura" e verificação de suas sínteses, reconhecendo a sua construção "como uma estrutura complexa" (2001: 160-1). Rossi propõe o método histórico como aquele mais capaz de verificar qualquer hipótese sobre a cidade, por ser ela, "por si mesma, depositária de história", tratando-a não apenas como artefato mas como texto, não apenas em sua materialidade mas com relação à "ideia que temos da cidade como síntese de uma série de valores" que concernem à imaginação coletiva (ROSSI, 2001: 194). O método histórico seria o único positivo porque "as cidades se oferecem a nós através dos fatos urbanos determinantes, em que é preeminente o elemento histórico" (ROSSI, 2001: 193).

Objeto de medo e fascínio desde o século XIX, quando se constitui um saber específico e que se pretende científico sobre ela, o urbanismo, a cidade produziu uma série de discursos que aspiram compor saberes competentes, uma imagem globalizante para a qual Michel de Certeau utiliza a certeira imagem da Nova Iorque vista desde o alto do World Trade Center, olhar destruído por acontecimentos trágicos e recentes. A cidade panorama é, para Certeau, um simulacro teórico, portanto visual, um quadro que depende do esquecimento das práticas. O deus voyeur que cria essa ficção só conhece cadáveres, deve se abster do obscuro entrelaçamento de condutas diárias (1990: 141). É abaixo, nos limiares onde cessa a visibilidade que vivem os praticantes ordinários da cidade. Nas marchas cotidianas da cidade os passantes escrevem um texto ilegível, disfrutam de um espaço invisível para eles; têm um conhecimento desse espaço tão cego quanto o corpo-a-corpo amoroso. Os elementos escapam à legibilidade, é como se uma ilusão (cegueira) caracterizasse as práticas organizadoras da cidade habitada. O cotidiano remete a práticas do espaço, ou operações que escapam a um 
espaço geometrizado, geográfico, de construções teóricas e panópticas, às totalizações imaginárias do olho. Essas práticas constituem operações (maneiras de fazer), uma outra espacialidade, uma experiência antropológica, poética e mítica do espaço. "Uma cidade transumante, ou metafórica, se insinua assim nesse texto claro da cidade planificada e legível" (1990: 142). A vida urbana e cotidiana restabelece o que o projeto urbanístico exclui em seu discurso totalizante e quase mítico. Se o discurso do poder se "urbaniza", a cidade é dominada por movimentos contraditórios que se compensam e se combinam com o poder panóptico. São combinações de poderes sem identidade legível, sem transparência racional, impossíveis de se gerir (1990: 144-5). Por isso o historiador sugere o retorno das práticas da cidade e do cotidiano para a compreensão mas também para a fruição do urbano. A cidade conceito se degrada. Talvez elas deteriorem ao mesmo tempo em que os procedimentos que as organizaram. Os ministros do saber, que sempre supuseram o universo ameaçado pelas mudanças, transformam a desgraça de suas teorias em teorias da desgraça. Quando eles querem prender o povo no pânico de seus discursos, eles terão mesmo razão? (1990: 145).

Hoje nos defrontamos com outro desafio epistemológico, o que Melvin Webber e Françoise Choay, por exemplo, denominam o fim da era das cidades, a assunção de um mundo pós-urbano. Haveria, segundo Webber, uma deficiência da linguagem e uma visão anacrônica na maneira de pensar a cidade contemporânea. Faltam-nos termos adequados para descrever uma ordem social emergente. Supomos, por exemplo, que certos problemas da cidade são "problemas urbanos", partindo do pressuposto de que essas cidades se organizam da mesma forma que as sociedades do passado. Buscamos soluções locais a problemas que não são locais, que não podem ser resolvidos no nível municipal. Governos definidos territorialmente não podem resolver problemas cujas causas não têm relação com o território ou a geografia. Conceitos e métodos de engenharia e planificação urbana para instalações físicas unitárias não podem servir para um projeto de mudança social de uma sociedade pluralista e móvel, onde a importância da distância geográfica e do lugar estão em declínio. Até agora, a organização social coincidiu com a organização espacial. Hoje, as distâncias e as restrições espaciais diminuem. Desaparecem as diferenças culturais e de informação entre o homem urbano e o rural. Desaparece também a distinção territorial entre urbanitas e ruralitas. Os menos integrados na sociedade moderna não são mais os

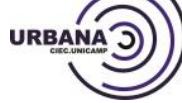


ruralitas, mas determinados habitantes das zonas metropolitanas (WEBBER, 2004: 1516).

Seguindo os passos de Webber e Choay, Paul Virilio afirma que, se a metrópole ainda possui uma posição geográfica, ela não se confunde mais com a oposição campo/cidade ou centro/periferia. A oposição intramuros/extramuros dissipou-se com a revolução dos transportes e o desenvolvimento das telecomunicações. A interface da tela (computador, televisão) cria uma representação nova: o elemento arquitetônico vive em deriva, flutua em um éter eletrônico desprovido de dimensões espaciais, mas inscrito na temporalidade única da difusão instantânea. "O protocolo de acesso da telemática sucede o do portão" (2004: 10). Não há mais separação por obstáculos físicos, com a interfachada dos monitores e telas de controle o algures começa aqui e vice-versa. O espaço é formado agora por uma topologia eletrônica na qual a imagem digital renova a noção de setor urbano. À antiga ocultação público/privado e à diferenciação de moradia e circulação sucede-se uma superexposição onde termina a separação entre próximo e distante, assim como nas distâncias a separação entre micro e macro.

As tramas da tecnologia não se inscrevem mais no espaço de um tecido construído, mas nas sequências de uma planificação do tempo, cuja interface é entre homem/máquina e não mais entre homem/fachadas dos imóveis, superfícies e loteamentos. A cidade se tornou uma unidade de lugar sem unidade de tempo, sem distinção dia e noite, no novo regime de temporalidade das tecnologias avançadas. A demarcação urbana não se refere mais a um lugar, mas a um tempo inscrito na TV e na eletrônica. A forma urbana não é mais uma demarcação entre aqui e ali, mas uma programação de um "horário". Apesar das promessas dos arquitetos pós-modernos, a cidade se encontra privada de portas mas os limites urbanos deram origem a uma infinidade de aberturas, rupturas e fechamentos igualmente constrangedores e segregativos (2004: 12). Estamos, pergunta Virilio, numa cidade sem portas? Onde ela começa? Ou estaremos no limite de uma porta sem cidade? (2004: 15)

"Graças aos satélites, a janela catódica traz a cada um dos assinantes, com a luz de um outro dia, a presença dos antípodas. Se o espaço é aquilo que impede que tudo esteja no mesmo lugar, este confinamento brusco faz com que tudo (...) retorne a esse lugar, a esta localização sem localização... o esgotamento do relevo natural e das distâncias de tempo achata toda localização e posição. Assim como os

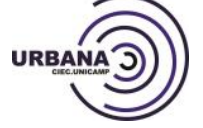


acontecimentos retransmitidos ao vivo, os locais tornam-se intercambiáveis" (2004: 13). Onde antes havia um teatro político da pólis, com a ágora e o fórum, hoje só resta uma tela catódica onde se agitam as sombras, os espectros de uma comunidade, onde o cinematismo propaga a última aparência de urbanismo, um urbanismo sem urbanidade, onde o tato e o contato cedem lugar ao impacto televisual. O espaço construído não é exclusivamente material, mas marcado pela proliferação de efeitos especiais que afetam a consciência de tempo e das distâncias, assim como a percepção do meio. Do ponto de vista do tempo e do espaço, das relações sociais, as telecomunicações e a sua imediatez fazem aquilo que não está presente ter prioridade sobre o aquilo que está presente (VIRILIO, 2004: 73). Isso representa o declínio da unidade de vizinhança e das políticas de organização territorial; declínio de um Estado nacional dividido entre reivindicações de autonomia interna e necessidades de alianças internacionais. Como caminhar pela cidade, que práticas de cotidiano serão possíveis neste espaço não mais definido decisivamente por seus limites espaciais, pela concretude das ruas e das fachadas?

Embora a estrutura da metrópole moderna continue dominando a imaginação social, as regiões metropolitanas não se adequam mais aos modelos clássicos. Há novas demandas de polinucleamento, que não seriam resultado de falta de planejamento ou espraiamento incontrolável das cidades, segundo Edward Soja, mas resultado de novas práticas sociais. Na era pós-metrópole, como define este autor, é cada vez mais difícil escapar da cidade, da condição urbana e da cidade como forma de vida ubíqua. Isso mudou também as formas como a cidade é modelada pela classe, raça e relações de gênero, cada vez mais complexas e opacas (2000: 238). O que ele denomina Exopolis. Exopolis pode ser definida como a cidade virada do avesso, mas também para fora, uma globalização da Inner City (centro degradado da cidade), que coloca as periferias no centro, redefinindo os conceitos de Outer e Inner City. O centro de Los Angeles, exemplo clássico de uma Exopolis, concentra os empregos na pós-metrópole policêntrica. No meio dos enclaves do lado este está a zona chamada Skid Row uma área urbana pobre com tabernas, bares baratos e hotéis dilapidados frequentados por delinquentes, alcoólicos e itinerantes. Os sem-teto provavelmente superam os moradores com casa e emprego da região, apesar das tentativas de gentrificação. 0 centro é um arquipélago de enclaves, mas continua sendo um polo de atração e nó de

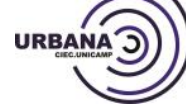


dispersão. Poucos centros revelam tão bem a cidade virada do avesso, núcleo e periferia entrelaçados no mesmo espaço e tempo como o de Los Angeles (2000: 254).

O espraiamento da ação e da ocupação espacial tem levado a uma luta por justiça espacial e uma nova consciência cultural e política, que pode ser chamada de democracia regional, representada pela aliança de trabalhadores pobres chamada Bus Riders Union, para defender os interesses dos dependentes do trânsito, sobretudo imigrantes pobres do centro. Ela luta contra a discriminação destes trânsitodependentes por políticas públicas que antes favoreciam apenas aos brancos de classe média, conflito de uma atualidade desconcertante para os que habitam as grandes cidades brasileiras. Nesse movimento há uma intersecção de raça, classe e gênero, com efeito na geografia da pós-metrópole, expandindo as noções tradicionais de direitos civis para políticas espaciais mais específicas, criando novas visões de cidadania democrática e direito à cidade. Na Exopolis se formaria uma nova política cultural que trata da desigualdade não focando nas lutas políticas definidas por rígidos canais de resistência baseados em classe, raça e gênero, mas por meio de alicerces transversais e inclusivos de solidariedade, consciência coletiva e construção de coalizões. Seria um giro cultural (cultural turn), uma luta cultural que substituiria uma política socioeconômica, com o objetivo não apenas de reduzir as desigualdades mas redefinir como as desigualdades de status e poder são utilizadas para alimentar exploração econômica, dominação cultural e opressão individual (SOJA, 2000: 279).

Um caminho que não é feito sem conflitos, como recorda Tereza Caldeira em trabalho já clássico sobre a segregação em uma das cidades mais exemplares neste aspecto, a São Paulo dos muros. Com o crescente medo do crime, a intolerância com os grupos sociais diferentes aumenta e não se tem interesse em procurar soluções comuns para os problemas urbanos. A solução encontrada pelas elites e pelos poderes públicos é sempre o distanciamento social nos enclaves fortificados. Uma cidade de muros se forma na qual a qualidade do espaço público piora enquanto se consolida a democracia; quanto mais democracia mais se resiste ao seu avanço pela criação de dispositivos de controle e segurança que separam, segregam e descompõem os espaços públicos por meio de estratégias privadas. A segregação pode ser vista como uma reação à democratização, pois serve para estigmatizar, controlar e excluir aqueles que acabaram de forçar seu reconhecimento como cidadãos e seus direitos (2003: 255). 
Ao pensar um dossiê sobre a História Urbana, a Revista Urbana pretende ressaltar o caráter ineludivelmente histórico da compreensão do fato urbano, o método mais eficiente para a sua compreensão, segundo Aldo Rossi; não apenas como uma recuperação historiográfica dos fatos que condicionaram o desenvolvimento dito histórico desta ou daquela cidade, a sucessão de estilos arquitetônicos, mais ou menos imbricados no espaço da cidade, o repertório de diagnósticos e projetos urbanísticos, por vezes incompletos, mas pensar a própria historicidade de nossos conceitos de cidade, de sua definição como lugar da História, onde ela se faz, se escreve, se define com um texto próprio, mais ou menos legível seguindo Certeau. Considerada sempre em sua materialidade, nos usos cotidianos, na relação do corpo neste espaço e seus deslocamentos, a Carne e a Pedra de que nos fala Sennett, sem esquecer-se das estratégias de segregação que a compõem, pois não há cidade sem divisão do trabalho, portanto, não há cidade sem desigualdade; a cidade é campo de ação de um poder, como recorda Braudel, e todo poder se exerce num espaço. Ela impõe suas comodidades mas também a sujeição. Pois como recorda o Vocabulario Portuguez e Latino de Raphael Bluteau, de 1712, a cidade além de "uma multidão de casas, distribuídas em ruas e praças, cercada de muros", é "habitada por homens que vivem em sociedade e subordinação".

\section{REFERENCIAS}

BRAUDEL, Fernand. Civilisation matérielle, économie et capitalisme. XVe-XVIIIe siècle.

V. 1. Les structures du quotidien: le possible et l'impossible. Paris: Armand Colin, s.d.

BRESCIANI, Maria Stella Martins. Metrópoles: as faces do monstro urbano (as cidades no século XIX). Revista Brasileira de História. São Paulo: ANPUH. 5(8/9): 35-68, set./abr., 1984-1985.

CALDEIRA, Tereza Pires do Rio. Cidade de muros. Crime, segregação e cidadania em São Paulo. Trad. port. 2. ed. São Paulo: Edusp, 34, 2003.

CALVINO, Italo, As cidades invisíveis. Trad. port. Diogo Mainardi. São Paulo: Companhia das Letras, 1994.

CERTEAU, Michel de. L'invention du quotidien, v. 1, Arts de Faire. Paris: Gallimard, 1990. 
CIEC

CHOAY, Françoise. O Reino do Urbano e a Morte da Cidade. Projeto História. Trad. port. Eveline Bouteiller Kavakama. São Paulo: Educ, 18: 67-89, maio, 1999.

LEPETIT, Bernard. Tentons l'expérience. Annales ESC. Paris, 6: 1317-1323, nov./dec., 1989.

. Por uma nova história urbana. Org. Heliana Angotti Salgueiro. Trad. port.

Cely Arena. São Paulo: Edusp, 2001.

ROSSI, Aldo. A Arquitetura da Cidade. Trad. port. São Paulo: Martins Fontes, 2001.

SENNET, Richard. Carne e Pedra. O Corpo e a Cidade na Civilização Ocidental. 4. ed.

Rio de Janeiro: Record, 2006.

SOJA, Edward. Postmetropolis. Critical Studies of Cities and Regions. Oxford, UK: Blackwell, 2000, pp. 233-321.

VIRILIO, Paul. O Espaço Crítico e as Perspectivas do Tempo Real. Trad. port. São Paulo: 34, 2005.

WEBER, Melvin. La Era Postciudad. In: VV. AA. Lo Urbano en 20 Autores Contemporáneos. Barcelona: ETSAB, UPC, 2004, pp. 13-23. 